\title{
Is archaeology conceivable within the degrowth movement?
}

\author{
Nicolas Zorzin \\ Institute of Archaeology, National Cheng Kung University, Tainan City, Taiwan \\ Email: z10608010@email.ncku.edu.tw.
}

\begin{abstract}
Since the 1980s, archaeology has been further embedded in a reinforced and accelerating capitalist ideology, namely neo-liberalism. Most archaeologists had no alternative but to adapt to it through concessions to the free-market economy and to the so-called mitigations taking place within development. However, it is now apparent that the ongoing global socio-ecological disaster we are facing cannot be reversed with compromises but rather with a radical engagement against the injunctions of competition and growth. I suggest that we must anticipate the necessary transformations of archaeology in the coming decades, before archaeology becomes a technical avatar of the neo-liberal dogma, or before its complete annihilation for being deemed 'superfluous' (Wurst 2019, 171) by the capitalist regime. In this paper, I will use the idea of 'degrowth' to propose a new paradigm for archaeology by applying the concepts of civil disobedience, voluntary simplicity, redistribution of means and the ethics of no-growth.
\end{abstract}

Keywords: Cultural resource management; archaeological practice; neo-liberalism; degrowth; radical engagement; future of archaeology

\section{Opening new horizons}

This contribution aims to continue the debate opened by James L. Flexner (2020) in Archaeological dialogues, over the current 'degrowth' movement and its hypothetical impact on archaeological practices. It explores the possible outcomes of the combination of archaeology and the degrowth movement, which comes with the unavoidable preliminary task of providing a political-economy contextualization. This contextualization consists of retracing the origin of the resistance against an ideology which relies essentially on the idea of a 'free' competitive market economy, within which archaeology has been largely participating, from which it has benefited, and in which it has developed. To structure my arguments in this contribution I propose to (1) define succinctly the nature of this ideology, best described as 'neo-liberalism', before trying to (2) define a potential alternative, and (3) explore the implications of the degrowth movement in archaeology.

This article should be understood as a continuation of previous publications where I address the current configuration of the capitalist structure and its archaeological organizational expressions, mainly from a Marxist critical perspective (see Zorzin 2011b; 2015a; 2015b; 2016a; 2016b). I do not intend to reiterate these analyses, which concern material conditions, labour, class struggle and alienation, even though they remain in the theoretical background of this contribution. Instead, I would like to explore further and focus on the possibility of conceiving, choosing and collectively experimenting with an alternative organizational system for archaeology, inspired by what is called today the degrowth movement. Degrowth refers here to a politico-economic radical reorganization which problematizes capitalism. Degrowth shares with Marxism the idea that 
capitalism is simply a mode of production driven not only by growth (despite the term 'degrowth' - 'deaccumulation' would be a more accurate term), but primarily by competition for profit, and lately, by the neo-liberal 'craze for turning over global natures ... to marketoriented management' (Moore 2017, 177).

I am aware that 'degrowth' is still mainly an abstract project, rarely materialized, and that some ideas must be discussed in idealistic terms, which runs the risk of being perceived as naive, partially ungrounded or unrealistic. Yet this is precisely the aim of this contribution: to trigger 'le réveil des imaginaires' (the awakening of the imaginaries) (Damasio 2020), in opposition to the Thatcherite mantra 'There is no alternative'. The aim is thus to induce a collective exploration, in our respective contexts, of our own imagined, necessarily troublesome, solutions, even though they can hardly be entirely satisfying until we have opportunities to put them in practice in the coming decades.

\section{Defining or redefining a concept resisting definition: neo-liberalism}

One of the main issues posed by the ideological-structural system humanity is now dominantly living in lies in its resistance to being defined (Mirowski 2018; 2014). Defining the contours of an idea makes it a tangible 'thing', which can be recognized for what it is by all and potentially identified as an ideological programme to concur with willingly or be fought against. In both cases, populations living in 'democratic countries' are expected to be fully aware of the aims and effects of a doctrine proposed or implemented, but the main characteristic of the current neo-liberal doctrine is precisely its denial of being one (Altman 2005). Its claim is to be 'above politics' or to be 'apolitical', i.e. too 'common-sense' to be defined and seriously challenged (Hall and O'Shea 2013, 8-24; Waterton and Smith 2009, 13; Hale 1990, 7, in Hutchings 2018).

What exactly are we talking about when we use the term 'neo-liberalism'? For some of its most vocal opponents, neo-liberalism has been generally defined as a 'programme for destroying collective structures which may impede the pure market logic' (Bourdieu 1998). More precisely, as 'a political project carried out by the corporate capitalist class as they felt intensively threatened [from the 1920s to the 1980s], so in many respects the project was a counterrevolutionary project' (Harvey 2016). It was 'undermining unions, and other forms of association ... meanwhile it was transferring decisions to unaccountable private power, all in the rhetoric of freedom' (Chomsky in Lydon 2017).

On the contrary, many would continue to assert that 'neo-liberalism' only exists in the minds of its leftist opponents (Altman 2005; Peck 2013; Burns 2014, 260; Brick 2014, 875, in Mirowski 2014, 2-3): neoliberalism 'is a term commonly used by the left to describe the market-friendly, globalist policies' (Lopez 2017). 'This term has a wide variety of definitions and is used less frequently by its proponents (who prefer to speak of its component parts, such as free trade, privatization, deregulation and investor's rights) than by its critics on the Left, who see it as a package of inter-related policies' (Swift 2014, 29-30).

Openly or not, the aim of such ideology is to transform humankind into a flexible and mobile mass, free from its stases (i.e. divested from its needs for stability, commons, protection and solidarity, thus divested from the fundamental characteristics which one could define as 'humanity' or as a 'human society'), which make it unfit for the new globalized environment constituted of open, competitive and unquestionable flux and transactions (Stiegler 2019b). As such, neo-liberalism can be defined as

The extension of market dominance to all spheres of social life, fostered and enforced by the state. In economic policy, this means deregulation and privatization. In culture, it means untrammelled marketing and the commoditization of everyday life, including the intimate sphere (Scialabba, cited in Radio Open Source 2017). 
The main concern of a neo-liberal logic is to constantly revitalize competition at all levels in society, as a mindset. The now almost universally accepted competitive 'rules of the game' come with the belief in equality of opportunities to succeed for all, through unbridled struggle between everything and everyone. Neo-liberalism, as such, has been very successful, because it gives the masses a sense of purpose, within the framework of so-called 'fair competition' and 'unlimited growth'. The often underestimated major achievement of the neo-liberal doctrine is indeed its cultural hegemony among populations, implemented without much visible coercion. The colonization of people's minds has been extremely efficient. To a certain extent, we all have been neo-liberalized, in the sense that we believe consciously or unconsciously that we 'must' adapt to the current environment. Instead of challenging the status quo by uniting and by radically shifting our ways of life, we continue to compete within it to prosper economically (Latouche 2019a, 8) or to survive (Stiegler 2019a).

Yet this ideology is reaching its limits faced with both the environmental crisis (Servigne and Stevens 2015) and rebellions of an increasing part of the populations against what was revealed as a self-destructive ideology (Cervera-Marzal 2016; Kempf 2009). The COVID-19 pandemic might become a catalyser for both. Yet what has been attempted globally in the fight against COVID-19 so far was only addressing an epiphenomenon resulting directly from the ecological crisis, which remains largely ignored.

Against today's ongoing ecological and social crisis, one can observe two distinct avoidance strategies implemented by various neo-liberal governments:

1 Facing the global ecological crisis, some apply a 'green-capitalism' recipe, which claims that growth is entirely compatible with ecological sustainability (Tanuro 2013), while others openly use denial or manipulation of facts to avoid changing privileged humanity's self-destructive behaviours (Servigne and Stevens 2015, 222-223).

2 Facing social crises fuelled by rapid impoverishment and rising inequalities, neo-liberal governments use repression and structural violence (Sizaire 2019) to contain the contestations rising against the neo-liberal order.

In this very particular context, what stances, as citizens and as professionals both in archaeology and in cultural-heritage fields, can we adopt?

I believe two processes can be simultaneously engaged to thwart this new order:

1 a decolonisation of our neo-liberalised collective psyche (Chomsky 2013, 185; Latouche 2004; 2015a; 2019a, 36-37; 2019b) and

2 a grouping of communities' radical actions, using the degrowth movement as a concrete instrument of emancipation, with global effects expected in the long term (Latouche and Jappe 2015; Latouche 2019a; 2019b).

\section{What is degrowth?}

Degrowth could be defined in simple terms as a social movement advocating a global downscaling of production and consumption to face collectively both environmental disasters and social inequalities. Historically, the term 'degrowth' comes from French: décroissance, and was first used as such by the post-Marxist ecologist André Gorz in 1972 (Kallis, Demaria, and D’Alisa 2015, 1) as well as by Illich and Castoriadis (D'Alisa, Demaria and Kallis 2015). These authors were already firmly opposing the supporters of growth (it should be noted that in the 1970s-1980s, the principles of growth and progress were shared by both opposed dominant blocks, capitalist and communist). From a Marxist perspective, attitudes towards degrowth are still divided and 
sometimes opposed (Demaria et al. 2013, 206). Some orthodox interpretations of Marxist theory reject degrowth because their readings are closely embedded into ideas of progress and socioeconomic growth. Furthermore, some authors, such as Altvater, seem to suggest that degrowth is not obviously opposed to capitalism but only an inevitable step in its eventual collapse (Demaria et al. 2013, 206, citing Altvater). Altvater makes the point that 'reduction of growth is inevitable', but the fundamental difference between that phenomenon as a 'collapsing capitalism' and a 'degrowth movement' is that the latter is a well-informed choice and an experimental path taken by some individuals or groups of individuals to accelerate the collapse of the neo-liberal order and prepare for a truly post-capitalist society. However, there are also neo-Marxist authors, such as David Harvey $(2005 ; 2016 ; 2017)$, who are in line with the approaches proposed by the degrowth movement.

In the end, the term 'degrowth' has never meant 'declining', 'weakening', 'stagnating', and 'lessening' (Latouche and Jappe 2015). Instead, degrowth is a revolutionary project, in the sense that it offers a radical sea change in contrast with the competitive and growth-based society we are living in. After emerging from an unlimited growth economy, either through choice (i.e. through collective resistance or revolt), or through the coming forecasted socio-ecological disasters (Spratt and Dunlop 2019), degrowth aims to build a relatively prosperous, collegial society without growth (Jackson 2017). A society of degrowth is not a global alternative per se but rather a matrix of multifaceted alternatives, which mostly still need to be invented and adjusted to local (deteriorated or not) environmental and sociocultural specificities. I will now follow with a more detailed analysis of the concept of degrowth and its uses.

Degrowth as a scarecrow Often the first reaction when someone uses the term 'degrowth' is to compare it to an anachronistic desire to return to a Palaeolithic way of life, assuming that it will bring humanity back into stagnation at best, or as 'cave dwellers' at worst (American businessman Andy Kessler quoted in Pethokoukis 2017). The term also provokes condescension, with critics presenting it as a backward-looking, outdated and regressive idea, which has already lost the fight of 'reason' (see Pinker 2018, as the champion of the high-tech 'progressist' forces): 'Economic growth provides the wealth and technologies needed to lift people from poverty while simultaneously lightening humanity's footprint on the natural world. Rather than degrowth, the planet - and especially its poor people - need more and faster economic growth' (Bailey 2018, in Reason, a think-thank ultraliberal/libertarian magazine).

Another common accusation formulated against degrowth is to define it in a derogatory way as the new 'utopia' of our time, mostly carried out by radical environmentalists, such as Greta Thunberg, opposing the globally accepted sustainable-development 'liberal consensus' (Redclift $2005,220)$. Some others consider it a utopia far too frightening because it does not yet propose concrete and clear alternative models (Schwartzman 2012, 123-124), and could incapacitate some individuals, notably through 'eco-anxiety' (Faubert 2019). Furthermore, degrowth is sometimes criticized, even by its own advocates, for being too abstract and too weak to be taken seriously, because it suffers both from the tendency to not be supported in academic writings by 'rigid hypothesis testing', and from an absence of analyses of 'potentials for non-market value creation' and identification of 'concrete well-being benefits' (Weiss and Cattaneo 2017).

Among its supporters, Kallis and March (2014) also define degrowth as a utopia because it is nowhere to be seen. There is theory and there are small experiments broadly inspired by degrowth, but there is no spatialized "degrowth world" in its full plentitude' (ibid., 2). Even though the term 'utopia' can be used to define degrowth, it is time to face the fact that today's utopia (i.e. the dream of a perfect world) tends to lie exclusively in the neo-liberal dogma supporting 'the cultural logic of a socially and environmentally unsustainable growth' (Prádanos 2018), based essentially on primitive accumulation strategies, and fuelled by archaic extracting economic surpluses. Bailey's argument for more and faster growth (see above) is indeed the real utopia of the post-1970s world, even though its believers are in total denial of its current failure: 
Today, a lack of realism no longer consists in advocating greater well-being through degrowth and the subversion of the prevailing way of life. Lack of realism consists in imagining that economic growth can still bring about increased human welfare, and indeed that it is still physically possible (Gorz 1980, 13).

In my view, degrowth has no utopian vocation, but rather has a transitional and inspirational function towards a no-growth society, which can only be far from perfect, because it will necessitate significant efforts and sacrifices during and after the process of transition from our current market-economic competitive-based ways of life. Ursula K. Le Guin's fiction The dispossessed (1974) is a good illustration of this neither utopian nor harsh dystopian process. This we could define as an anarchist 'atopia' (Flexner $(2020,160)$ defines it as a 'concrete utopia') i.e. a transformation occurring in an inhospitable Earth which cannot be turned into a prosperous dwelling (any more) but where humans survive (not thrive) in the best sustainable way, socially and ecologically. Now, and in contrast with the many critics of degrowth, what the concept might truly embed is that the dogmatic neo-liberal imaginary based on growth needs to be replaced by a new one, i.e. a need to establish urgently 'a new common sense', which could rise as a 'postgrowth, decolonial, ecofeminist ... and postcapitalist imaginary' (Prádanos 2018, 15). This is done by overpowering the current schizophrenic injunction of 'sustainable development' as an economic form of 'colonialism in disguise' (Escobar et al. 2019) which generates a malaise and a global existential crisis (Daly 1993, 267-268). This new imaginary, starting with a decolonization of our everyday vocabulary (see D'Alisa, Demaria and Kallis 2015; as well as Le Guin 1974; and Damasio 2020), could then give rise to a new human society by creating the conditions necessary for its emergence.

Degrowth as political activism - or, in the end, how to 're-enchant' (Latouche 2019a) a 'disenchanted world'? (Weber 2003, 83). As underscored by Latouche (2019a), despite obvious signs of weakness after the financial crisis of 2008, the neo-liberal order has a strong ability to maintain things as they are and to disrupt any kind of potential evolution coming from activist movements (Latouche 2019a, 109). It was once believed that the re-enchanting of the world would pass through the grand soir (i.e. the 'revolution', as the necessary myth of the working-class movement to support its development). However, nowadays a revolution can only occur through the advent of a wave of mass 'economic atheism', a dis/de-belief in growth and competition, a renouncement of the ritual of consumptions, and a global agnosticism about progress (Latouche 2019a, 113). This decolonization of our minds, expectedly judged as unrealistic by many, would nonetheless constitute the prerequisite to a construction of a new society based on conviviality, autonomy and frugality, and resulting in a form of sustainable no-growth society. This would be established not as a religion or a cult, but rather as a philosophy, a 'wisdom' (from French sagesse, in Latouche 2019a, 114). It is thus a bet on the maturity of our contemporaries, and on our abilities, first, to expose the failure of our macro-economic structures leading the capitalist oligarchy to be disarmed and neutralised (Latouche 2015b, 95; see also Piketty 2019, illustrating that inequalities are an ideological choice, not a fatality), and, second, to foresee and implement other ways of living and other sets of values (Latouche 2019a, 120).

To do so, propositions and attempts to implement an agenda have been formulated in different forms, from which a sequence can be used as a simple schematic basis for our reflection: (1) anti-growth, (2) alter-growth, (3) degrowth and (4) no-growth. This sequence is not restricted to a succession of steps in a linear fashion. The initial three steps suggested here can be implemented simultaneously and/or in various orders, aiming, in the end, to establish a no-growth society. 


\title{
The general failure of archaeology in the neo-liberal economy, namely salvage/ commercial archaeology, and cultural-heritage management (CRM)
}

\author{
Through the concomitant processes of colonization and globalization ... local or 'traditional' \\ heritage stewardship strategies were - and continue to be - extinguished, replaced by capitalist \\ heritage regimes focused on large- or industrial-scale resource extraction, production, and \\ consumption
}

Hutchings (2018, 71, quoting Bodley and Ross).

During the last decade, I dedicated most of my research efforts trying to deconstruct the mechanisms which affect archaeological practices within the neo-liberal system around the globe (Vandevelde-Rougale and Zorzin 2019; Zorzin 2011a; 2013; 2015a; 2015b; 2016b; 2017). Many others tackled critically the situation of archaeology and cultural heritage (Parga-Dans 2019; Hutchings 2018; Aparicio Resco 2016; Hutchings and La Salle, 2015; 2013; Kehoe 2007; Hamilakis and Duke 2007; Hamilakis 1999; 2015; Shanks and McGuire 1996). All these analyses pointed out a major and problematic shift faced by archaeologists during the 1980s and 1990s, with major consequences today: a global reform of archaeological practice toward a commercial form, privatized, competitive and profit-oriented, making the discipline market-compatible, and so 'adapted' to the new neo-liberalized environment, as defined previously by Stiegler (2019a; 2019b).

Even though few within the archaeological community would phrase it this way, the discipline was then made complicit in neo-liberal doctrinal standards (Hutchings 2018, 83), which happened increasingly fast in academia (Wurst 2019, 169). It took place with the consent of most archaeologists who, legitimately (as Canadian archaeologists confided to me in 2008; see Zorzin 2011b, 249-687), wanted to 'live with their time', and 'to find the best way to deal with this unchallengeable reality' which, it should be remembered, occurred in a period of fast increase of wealth, despite cyclical crises (Guay 2019).

As was emphasized by Yannis Hamilakis in 1999, that new relationship might have constituted the initial 'betrayal' of archaeologists to the intrinsically intellectual and social natures of their work. Yet, reflecting on the neo-liberalization process, and considering neo-liberalism as an insidious and hidden ideological colonizer, it would be misplaced to accuse archaeologists of deliberate betrayal, as most of them are not aware of what exactly they were getting into. Archaeologists could certainly not have foreseen the consequences of the reforms, mostly consisting of the privatization of their activities, which was, as stated by my interviewees around the world, the most 'natural', 'logical', 'common-sense' way to do archaeology at the time (Zorzin $2011 b)$. It was indeed a time of great opportunities for an increasing number of people to become professional archaeologists, free from state or academic limitations. For a short period, privatization was a truly liberating, self-empowering and intellectually stimulating change for many archaeologists. In the long run, however, it was a misleading choice.

Furthermore, it should be clarified again that in a post-1980s context, no clear distinction can be made between the work environment of 'commercial', 'state' and 'academic' archaeologists (see Gil 2009; Wurst 2019), because they are all working in the same neo-liberal framework, made equally cost-efficient at many different levels by the institutions they are working for (Zorzin 2016a). Nonetheless, another clarification is important here, even though endlessly repeated through the years (Hutchings and La Salle 2013, 1-3; Zorzin 2015b, 792-793; 2011a, 120-121; 2010); critiques of the values of institutions are by no mean personal critiques. Even though 'commercial archaeology' is now dominant or mainstream, it should not be absolved of critique or responsibilities. Unfortunately, this distinction and the subsequent necessary detachment needed from everyday practice seem a challenge for many (Hutchings and La Salle 2013, 2-3). 
For at least two to four decades after implementation, the new neo-liberal governing paradigm ended up 'fetishizing' (Hamilakis 2007, 23) and 'commodifying' (McGuire 2007, 10) the archaeological discipline as a technical tool (Hutchings 2018, 82). Through this it was largely emptied of its original scientific research-oriented goals, erasing its social connection through professionalization and nullifying archaeologists' working traditions of living willingly on the margin of capitalist society (Everill 2009, 83-103). It furthermore degraded the working conditions of archaeologists, as well as the traditions of solidarity within the working community (Vandevelde-Rougale and Zorzin 2019, 110).

All in all, it comes back to two fundamental questions. First, for whom are we doing archaeology? Remembering the fact that archaeology is not only about science and techniques, but mostly about domination of political power (McGuire 2007, 10). Second, for what future are we doing archaeology? Stating firmly that only a 'shift ... towards the making and shaping of collective futures ... will build capacities for archaeology and heritage to be more effectively connected with the social, economic, political and ecological challenges of our time as their future solutions' (Högberg et al. 2018, 645). Recently, Hutchings (2018, 80-81) has emphasized the fact that neo-liberalism has been successfully implemented in archaeology and that most archaeologists now prefer to 'play by the rules of the game', despite severe warnings (Aparicio Resco 2016; Hamilakis and Duke 2007; Hamilakis 1999; Shanks and McGuire 1996). Hutchings (2018, 80-81) explained this dominant tendency towards a 'sustained optimism', 'resourcism' or extractivism as a neutral approach, uncritical and/or unaware of the doctrine it is embedded into. In order to survive, 'optimism' based on exploitation of limited resources has to rely heavily on concepts such as 'sustainable development', perfectly 'adapted' to the neo-liberal authoritarian strategy of pretending to fight climate change, environmental degradation and destruction of cultural heritage, but in fact willingly ignoring them (i.e. green-washing destructive policies). Yet 'to ignore or forget is to externalize capitalism's gruesome toll on natural and cultural heritage' (Hutchings and La Salle 2013, 1). Whether living in neo-liberal democracies or autocracies, this is the situation that we are experiencing now: archaeology is de facto deeply embedded in the neoliberal logic (Zorzin 2015a; 2015b).

\section{How can degrowth contribute to entering a new paradigm in archaeology? Some illustrations from France and Canada}

I suggest that the response to the existential crisis provoked by the logic of growth must be a radical one. As Hutchings $(2018,81)$ defined it, it is through a 'deconstructivist postmodernist' approach that archaeologists can take a stance against the utopic and self-destructive logic of growth and make a socio-ecological commitment towards populations and cultural-heritage preservation, as a collaborationist attitude towards development and competition is no longer viable.

As a matter of fact, if archaeological or cultural-heritage sites are considered and defined as 'resources', their exploitation, displacement or destruction will be regarded as acceptable or as a lesser evil than slowing down economic development. Furthermore, a resource is expected to be exploited and depleted at some point, which is entirely oxymoronic for archaeologists and cultural-heritage managers who are supposed to be working for the preservation of the human past.

As an answer to that situation, the degrowth set of ideas could help archaeology to challenge the toxic software which has become the currently dominant commercial/contract-managed archaeology almost everywhere on the planet. As such, I would like to assemble some propositions for the future practice of an archaeology as a radical degrowth actor. 
Degrowth as 'civil disobedience' (Thoreau 2017) Civil disobedience represents a first possible action which can support the degrowth movement, simply by opposing the structural violence of the neoliberal order (Louis 2014). Today, the concept is often used in the context of global ecological struggles, aiming at shifting some cultural norms to discourage unsustainable levels of consumption. It is also current in some political/humanitarian activism, for example concerning occupation and the use of native populations' lands, the mistreatment and abuse of minorities or refugees. However, it is also used, for instance, against utilitarian laws that encourage the commodification of the commons, which sometimes causes structural oppression of certain classes of people.

This approach might seem obstructive through its appearance as a blunt and unethical agenda, but civil disobedience tends to be much more effective and sturdier (in relatively functional democracies) when it is associated with propositions of constructive alternatives (Renou $2015,164)$. As such, a development project, or even a research project, causes various issues for the archaeologists involved: ethical questions on identities, memories, ownership, colonization, methodological problems, etc. In certain cases, it creates an intolerable dissonance for the archaeologists who try to accomplish their tasks but are forced (by both financial and time pressures, weak or nonexistent enforcement of legal protections, and quality standards defined by ticking boxes) to create a low-quality 'product', irrelevant and invisible for most.

In situations of this type, and especially if they are recurrent, the only way to preserve moral integrity and personal and professional dignity, and to avoid depression or painful self-denial, is to act. Actions can take many different forms, from collective resistance to orders (i.e. not doing as instructed - see Zorzin 2016b, 320-321), to unionization (see Unite Archaeology, for example, in Ireland since 2014), to active sabotage. The strength of an action of civil disobedience is proportional to the numbers of actors involved and its duration (Ott 2019, 41). For example, 'sabotage' (which can be simply translated as the implementation of an 'archaeological work ethic' in an alienated archaeological context) can be achieved by quietly increasing the excavation's standards, resulting in inflating the time needed to accomplish the task properly, or simply by taking the time to talk to the public. The latter two actions will certainly result in the paradoxical accusation from developers of archaeologists being provocatively 'unprofessional', while archaeologists are precisely trying to be respectful of the minimum ethical standards. Here, even though archaeologists are involved in a non-violent collective action they will certainly trigger different forms of repression (see Zorzin 2016b), which will amplify the importance of the initial revendication (Ott 2019, 41).

All these actions can potentially result in not getting future contracts, closing archaeological services, and even potential bankruptcy, but this, as we mentioned previously, is the unfortunate prerequisite to a refoundation. Yet if national laws continue to protect heritage (or if it becomes a community requirement in a post-capitalist system), the work and expertise of archaeologists will always be needed; not, however, in the form it previously existed. It is up to archaeologists to continue supporting the destruction of heritage for the interest of developers (corporate or state-controlled) or to refuse to play this role any longer and return frontally to political contestation, something that is unavoidable while dealing with archaeology and cultural heritage.

For archaeologists, instead of accepting being increasingly used as the architects of a sacralized process of not slowing down development, I would rather, in conformity with the slow and reflexive nature of the scientific method implemented in archaeology and the absolute necessity of its public involvement, again become so-called 'growth objectors' (from the French objecteurs de croissance - Mongeau 2007).

A radical opposition like this will automatically be joined with taking risks and with putting the entire professional archaeology community as we know it in danger. Yet this drastic turn could be the opportunity for a return to a pre-1980s situation (in a French context), i.e. with archaeologists being activists, often willingly fighting back against what they see as useless mega-infrastructure projects, and involved in sociopolitical conflicts (Vandevelde-Rougale and Zorzin 2019, 110). During that period, most French fieldwork archaeologists were operating without the security of a permanent job, and without regular incomes, even though many French archaeologists at 
the time could continue their archaeo-activist actions while receiving different forms of state unemployment or low-income financial support. Yet as the emancipation of workers/ archaeologists cannot be achieved without the minimum means to sustain both professional activities and a decent life, I would propose to counterbalance the major issues created by potential income losses or income insecurity by implementing degrowth as a redistribution process (see the third point below), precisely to avoid precarity and its deleterious effects.

At this point in the contribution, an important clarification needs to be made to contextualize this radical proposal of resisting or sabotaging neo-liberal management that can put archaeologists-workers in precarious positions. It would be legitimate to ask here how such an approach can be suggested, while not discussing its potential consequences. In fact, the impetus behind my reflection is based on first-hand experience as a field technician (on and off during the last twenty years, at the same time as being a precarious scholar). A large part of the ideas developed in this article emerged from some relatively successful attempts at joint group opposition in a specific archaeological mega-project in 2015 (See Zorzin 2016b, 312-321).

Since then, having directly experienced precarity, poverty, bleak living conditions and degraded health, and having had to deal with a massive student debt, a conclusion was reached within our group of field archaeologists: to renounce archaeology as a job and find another source of income, preferably more socially significant. We also came to an agreement that we could only go back to archaeology if it could be more meaningful (even with a modest income), and if we could regain full control of the fieldwork's aims, methodologies, interpretations and communication. Our working community mostly perceived commercial archaeology as an alienating practice, and as alienated by developers' managerial methods. At that time, it was impossible for any of us to see how commercial archaeology could fulfil our shared aspirations apart from the fact of earning an income (Flexner 2020, 161). As such, it was necessary to urgently distance ourselves from commodified archaeology and look for alternatives (see also Hamilakis 2015).

\section{Degrowth as voluntary simplicity}

[Voluntary simplicity is] a way of life that involves consciously minimizing wasteful and resource-intensive consumption. But it is also about reimagining 'the good life' by directing progressively more time and energy toward pursuing non-materialistic sources of satisfaction and meaning.

Alexander $(2015,133)$

Voluntary simplicity is indeed at the core of the disruption process of the neo-liberal order, through encouraging a cultural transition toward restrained consumption, ideally willingly implemented by people (but most probably by the absence of a choice because of recession or collapse). This transition will only be viable if a critical mass of individuals accepts the fact that wealth and material accumulation cannot be the basis for a fulfilled life, and that this accumulation is, in fact, toxic at the individual and the global level. In contrast, voluntary simplicity advocates seeking accomplishment in a life based on community and social engagement, equity between people, solidarity, fulfilling employment, intellectual and artistic projects, craftsmanship, political involvement and pleasure seeking (Stan 2007, 93). Following this logic, a resistance process could lead archaeologists to an exile from private and state structures (as suggested previously) regulated by the logic of the competitive market, to a reformation into independent structures (such as NPOs, cooperatives) or into amateur-based/citizen-controlled (Flexner 2020, 162) structures (associations, small municipalities).

For example, in the case of the current French semi-state-based archaeological system, this radical solution could be avoided if salvage archaeology could return to 2001's law situation, with an archaeology entirely protected from the competitive market economy. Yet, in the current 
dominant neo-liberal political framework this is a far-fetched perspective, and even more problematic considering that the state structure (Institut national de recherches archéologiques préventives - INRAP) for archaeology's 'polluter-payer' financial base still relies on growth and therefore cannot escape the competitive economic logic which comes with it (VandeveldeRougale and Zorzin 2019, 110-111).

However, considering the current situation in France, with almost no economic growth at a national level since 2008, the legal framework of 2003 opening archaeology to a competitive market accommodated the potential disappearance of archaeological structures if proven economically incompatible with or not 'adapted' (see Stiegler 2019a; 2019b) to the current free-market logic. This is already occurring in France, through bankruptcy of some private operators, but also through the downsizing or dismantling of archaeological services within local authorities (collectivité teritoriales), and through the slow death of INRAP, universities and research centres. This occurred predominantly through non-renewed departures for retirement, budget cuts, decreasing employment, precariousness and low salaries. In the short term, and in an unchanged neo-liberal framework, the most probable scenario for French archaeology is a collapse of the public sector, but a survival of few major private operators within an increasingly deregulated configuration, like the UK system (see Zorzin 2016b; Shepperson 2017). In the end, these might potentially be absorbed by major engineering or by infrastructure corporations serving only their own legal interests (Zorzin 2016b, 314).

This downfall scenario, however, could theoretically result in the creation of a new form of cooperative organizational structure for archaeology, or a reactivation of the old amateur network, which used to thrive in France before the 1970s. These new independent establishments could then provide a new framework to practise archaeology, placing autonomy and fulfilment at the centre of their craft. This means the pleasure of accomplishing a complex and meaningful task, the satisfaction of producing results, and the gratification of social interactions involving knowledge sharing, conviviality and solidarity. When the obligation of profit is eradicated, monetary needs would be limited to supporting a decent life for archaeologists and their families - nothing less, nothing more.

Additionally, we should note that the concept of 'voluntary simplicity' can also be applied directly to archaeological fieldwork. As such, the concept can challenge our excavation methodologies, which currently still emphasize the questionable extensive and expensive process of artefact and data accumulation. Against this accumulation process, a minimalist approach combining a large panel of non-destructive operations could be implemented: underground non-invasive detection combined with digital recording technologies, targeted small trenches and a zero-waste policy could also considerably change the look of our still mostly extractivist activities. This should come with a simultaneous redirecting of our practices and aims toward community involvement, such as that suggested by Flexner $(2020,166)$ involving a 'slow-science' model in which open discussion and 'storytelling' take precedence over the accumulation of data.

Degrowth as a redistribution process In a society of degrowth, work aims at satisfying the needs of the community instead of the urges of material possession. A degrowth economy is, then, an opportunity to exchange goods and services on a small scale and an occasion to contribute to community life according to one's skills and knowledge (Mongeau 2007, 134).

In term of redefining work and economy, a few different directions have to be explored: first, 'defining basic and maximum income' (Alexander 2015, 146-148) i.e. providing enough income for people to have a decent and dignified life but less income for luxury consumption; second, a 'job guarantee' (Unti 2018, 63), i.e. a decentralized program relying on local governments, nonprofits, and community organizations; and third, work sharing (Schor 2015, 195-197), meaning better-distributed job opportunities and working toward flexible working-hour norms, moving from 40 hours per week (five to six days) to 20-25 hours per week (approximately three days). This will avoid unemployment for many in a context of high labour productivity (notably due to 
mechanization and digitalization), and nevertheless will significantly reduce the annual carbon footprint and increase spare time for social and political activities (Schor 2015, 196). The main idea behind these propositions is to give workers an opportunity to maintain their independence (intellectual and physical) through the security of a basic income and/or through the guarantee of a job, and through limitations in monetary gains and in working hours/days, allowing them to avoid bank debts and dependence on an employer.

In the current climate, archaeologists implying the aforementioned disobedience and voluntary simplicity on a daily basis would be sanctioned or sacked. The solutions to thwart the loss of jobs and incomes organized in a capitalist fashion would be to provide a 'job guarantee'. This would work at the level of communities and NPOs and would consist of implementing archaeological programmes according to local (even modest) means and needs (such as free accommodation; free and fast Internet access; providing equipment, health coverage and free education for kids, for example). As such, archaeologists would eradicate their current financial precarity and permanent internal competition to get contracts within the free-market economy. Although they might lose in geographical stability, this type of employment requiring a certain mobility through time can prove to be truly meaningful for long-term community-based projects. In such a configuration, archaeologists would have to prioritize the needs of the community over their research and personal interests (see Le Guin 1974).

In fact, such an experimental configuration has already occurred. It happened without any 'degrowth' theoretical framework involved, but as an organic and intuitive development. In Quebec (Canada), an NPO called Archéo-08 has existed since 1985 as the result of an encounter between the citizens of a region, who expressed their desire to develop archaeological research, and an archaeologist, the late Marc Côté. Côté took up the challenge of a more independent archaeological project by moving to a remote area of Quebec with his family and essentially relying financially on the local community for material support, and on regional and national subventions (the Ministry of Culture and Communications, notably). The project was far from perfect, or financially stable, and involved a constant struggle to receive the financial means to support a long-term endeavour (according to dialogue established with Côté in 2008). One of the most astounding characteristics of the NPO was that it was populated by enthusiastic archaeologists who were proud of the results of their research and the quality of interactions with the local population. Even though embedded in an archaeologically competitive provincial system, the geographical distance of the NPO from urban centres (where the archaeological companies are based) played a buffer role, allowing its existence to be based in a different politico-economic form from the capitalistic one, and this continues to be so today.

The idea of a national/regional 'basic minimum income' (BMI), as the provision of identical payments from a government (national, regional or local) to all citizens to meet a person's or a family's basic needs, could empower labour over capital and 'strengthen the power of civil society to shape the priorities for the use of the social surplus and the organization of economic activity' (Wright 2005, 2). This is particularly relevant to archaeology where a BMI could not only guarantee that archaeologists proceed to their most visible work - the digging - but guarantee that they do analyses, research, publications and, most importantly, community-based involvement in the long term as well. The absence of means and time for these essential activities in market competitive archaeology is one of the main explanations for its loss of direction in recent decades (Högberg et al. 2018, 642-644; Vandevelde-Rougale and Zorzin 2019, 111). By providing a BMI, based on a non-competitive, non-profitable, co-constructed project within a community, an archaeologist or a team of archaeologists can plan, at least for some years, to establish themselves successfully as decommodified workers, and moreover as happy ones.

However, this said, a pattern that has emerged recently illustrates the ability of neo-liberalism to digest almost any form of ideological innovation initially hostile to it, and then produce a perverted version of the original defiant proposal. A corrupted BMI would then consist of stimulating constant consumption (aiming only to avoid recession and degrowth), as a new neo-liberal 
avatar coming to the rescue of the capitalist logic. In contrast to this, the BMI imagined/suggested in this article is seen as a truly redistributive system, which can only be foreseen at a small scale (a settlement, a city state, an eco-community) from which work can no longer be used to control and extract wealth from oppressed workers. Rather, it works 'to free people to pursue the kind of work they find interesting and fulfilling' (Flexner 2020, 162). Yet in my view a BMI should function as a transitional process during the distancing from the capitalist system until work becomes an instrument of proper emancipation at the service of a small-scale community who have chosen a 'subsistence-oriented way of life'. After this, a BMI should no longer be necessary. As Illich $(1980,52)$ notes,

There, the inversion of development, the replacement of consumer goods by personal action, of industrial tools by convivial tools is the goal. There, both wage-labor and shadow-work will decline since their product, goods or services, is valued primarily as a means for ever inventive activities, rather than as an end, that is, dutiful consumption. There, the guitar is valued over the record, the library over the schoolroom, the back-yard garden over the supermarket selection. There, the personal control of each worker over his means of production determines the small horizon of each enterprise, a horizon which is a necessary condition for social production and the unfolding of each worker's individuality.

\section{No growth as a sustainable society}

For the term 'sustainability' to finally gain meaning (again), it needs to be decolonized urgently, i.e. extracted from its oxymoronic meaning given by the neo-liberal dogma as an achievable and desirable goal conciliating economic growth and life sustainability on Earth (Jarrige 2016, 5; Sauvé 2007; and cf. the concept of 'green capitalism' mentioned earlier). 'Sustainable growth' needs to be recognized as a toxic concept serving two main purposes: first, justifying corporations', states' or individuals' unethical and unsustainable social and environmental actions which aim solely at short-term profits, and second, luring the masses into believing that they can redeem themselves from overconsumption with so-called responsible behaviour, while in fact maintaining the same self-destructive habits.

In contrast, it is within the informal economic strategies of small (eco-)communities, with small-scale farming and artisan work, that a form of 'economic localism' can take place to sustain a no-growth society:

the change in relations of production in terms of creating self-sufficient or even self-reliant communities ... would be geared exclusively by the choice to cover the basic needs of all citizens and those of the non-basic needs that citizens themselves decide to cover collectively, through their democratic assemblies and individually, through a voucher scheme and an artificial 'market' (Fotopoulos 2007, 14).

To define and manage the primary and secondary needs of a community, the concept of 'commons' can be of assistance (Parance and Saint Victor, 2014). 'The commons are usually understood in two primary senses: as 1) a paradigm of governance and resource-management, and 2) as a set of social practices in virtually all fields of human endeavour' (Helfrich and Bollier 2015, 75; see also Bollier 2014; Euler 2018, 1-18). It is easier to use the term as a verb: 'commoning', which defines all the processes of shared stewardship about things that a group benefits from and manages in common. The most important aspect of 'commoning' is its ability to regain ownership and control over the means of production, as well as its social commitment, the networking and the exchange of knowledge it involves in the management of a specific resource, being either nutritional, natural, territorial or cultural. The key in a successful management of commons would then 
be to clearly define what it is that we (the archaeologists and the communities concerned) would like to regain control over, and 'what is to be shared and how' (Helfrich and Bollier 2015, 76).

However, downscaling human life to small communities and restabilizing 'commons' will not be enough, and, as suggested by Latouche (2019a, 119-123), a step further in the establishment of a no-growth society is required, notably through 're-enchanting' our lives. Would this consist of creating new mythologies, new religious dogma? This is not the purpose or the intention; rather, re-enchanting is simply to give a space for people to dream once again and retake the necessary mental space for transcending reality.

As such, what 'degrowth' thinkers argue for is aiming to see the realities of the world from different perspectives, delivering new meanings, and creating new ways of thinking and new ways of doing, outside the neo-liberal matrix, and outside the disenchantment, apathy and smallness of our fully commodified lives. As such, poetry, aesthetics, art, music and potentially archaeology can today be the means to make us rediscover the sense of wonder of our childhood, as well as purpose and fulfilment.

Because the existence of archaeology has been progressively indexed on the level of urban development and infrastructural development, our social relevance cannot be taken in consideration any more, or only after demonstrating the financial viability of archaeology in the freemarket economy. This viability has proved untenable in a competitive configuration. Our 'production' remains unwanted by the dominant neo-liberal ideology, because, so far, archaeologists still represent a potential disruption of progress for developers and local governments, unless an archaeological site or a heritage site's preservation, or accidental destruction (cf. Notre-Dame de Paris burning in 2019), can serve electoral goals, gentrification, nationalist views or benefactors' interests (e.g. tax deductions). Moreover, a new strategy has been developed by numerous developers to commodify further an unwanted archaeology, by turning it into a 'green-washing' product with a very positive impact for the image of the company (see Zorzin 2016b, 323-324), exploiting the concepts of both 'social responsibility' and 'sustainable development', while being mostly socially and ecologically irresponsible.

In a degrowth economy, the concept of 'sustainability' could regain its full meaning, and archaeology could find its place within autonomous cooperatives, NPOs and associations, existing in close coordination with the aspirations of communities, by which these structures are partially or totally supported (as we saw above).

The existence of archaeology would then depend on the communities' consensus, consisting in defining archaeology as a non-basic need which is, nevertheless, an essential need to be covered for the well-being of the community, notably by establishing a 'sense of community and sense of place' through a 'convivial activity' (Flexner 2020, 163). It could become a pivotal and symbolic way of commoning.

Local citizens would therefore participate actively in defining how control could be reclaimed over heritage. This will be done in collaboration with archaeologists who would need to compromise in better integrating social demands and present needs about understanding and discussing the past in their agenda, as is already the case in community-based archaeology experiments around the globe (Atalay 2019, Moshenska 2017, Matsuda and Okamura 2011). However, community-based archaeology, also called 'public archaeology' (Flexner 2020, 164), is not necessarily absolved from neo-liberal, neo-colonial and self-serving agendas, or from being 'instrumentalized' and making irreversible damage to communities (Pudney 2019, 121). Indeed, it has often been disappointing to witness some public-archaeology projects becoming 'an orthodoxy within the social sciences reproducing the culture of silence around archaeology's pivotal role in the ongoing disempowerment of Indigenous peoples, their heritage, and their land' (La Salle and Hutchings 2016, 174, citing Menzies; see also Zorzin 2014).

As such, the future survival of a dissident, convivial, anti-capitalistic, non-self-serving archaeology will also depend on our ability to make it socially relevant. I believe that this will only be possible by letting go of the current technically fetishized, monetarized and politically neutralized 
archaeological practices to finally establish a 'craft archaeology': 'a socially engaged practice which is not alienating' (Shanks and McGuire 1996, 76). I suggest that this could happen with the essential help of creative expression and the artistic display of archaeological processes and results, aiming at a radical re-enchanting, as well as a radical critique, of neo-liberalism, and a decolonization of our dystopian consumerist realities.

I intend to experiment and explore further the possibilities offered by the association of artistic performances and archaeology, notably in Japan, and hopefully in Greece in collaboration with artists, performers, film directors and digital technologies. In this I am aiming at co-constructing (or 'co-producing'; see Flexner 2020, 164) new imaginaries for the present, for the past, for ourselves, for others, with others, and for the pleasure of sharing this with the community's members. Artists and archaeologists both have a pivotal role to play in the process of bridging the past and articulating it somehow in the present. Yet the fact that this type of archaeology is necessarily ephemeral, incidental, organic, unique to its context and fundamentally collaborative (Flexner $2020,165)$ makes it largely impossible to provide a descriptive prospect of what a performative archaeology in degrowth could or should look like.

\section{Concluding discussion: towards an insubordinate, post-capitalist future for archaeology?}

In the first part of this article, we saw that the neo-liberal imperative to 'adapt' to the acceleration of the commodification of all aspects of our lives successfully colonized most of humanity and established a cultural hegemony (Gramsci 1971). Yet the neo-liberal agenda has proved to be self-destructive ecologically through the injunction of growth, and socially harmful through the imperative of competition. It was then suggested that a movement called 'degrowth' could help structure resistance against this dogma. Instead of maintaining the status quo and despite the reluctance of many to face the unsustainable economic configuration we are living in, the degrowth movement suggests pushing towards another acceleration. The latter would aim for the ending of the current capitalist system and for the re-establishment of human interactions centred on a set of values such as social justice, empowerment, dignity, solidarity and collaboration, grounded in a set of possible common actions. Finally, we saw that archaeology was equally colonized by a competitive market-oriented mentality, even though archaeology has always been deeply implicated in the capitalist structures since its beginnings (particularly within colonial processes), and even though it is now paradoxically largely populated by a community actively seeking non-alienated work (Zorzin 2016a). In this part, some responses to the objectification of archaeology were presented, and confronted with some concepts aggregated within the degrowth movements: civil disobedience, voluntary simplicity and redistribution of means (and/or reappropriation of the means of production). Through some concrete examples, we explored how to prepare to transition towards a no-growth society, within which the current form of archaeological practices could no longer exist.

While we are constantly reminded that we have to adapt to the new reality, because we no longer have any other choice, and while we live in a time when 'reforms' are supposed to be compulsory, beneficial and urgent, few dare to name the nature of these changes which have affected archaeology since the 1970s, always presented as 'apolitical' and pure 'common sense'. The reality of archaeology is that it has been largely made compatible with the neo-liberal agenda: efficient, profitable, with a primacy for competition and economic growth.

Thus accepting the transitioning of archaeology away from its commercial practice could come with the advent of an archaeology of degrowth. Such a post-capitalist archaeology could reconnect with communities and engage itself in facing the current and future global fears of humanity concerning pandemic, industrial disasters (such as the proposed Fukushima project - see 
Schlanger, Nespoulous and Demoule 2016), pollution, economic recession, overexploitation, neo-colonialism and environmental and financial collapse.

As suggested by Antonio Gramsci in his Prison notebooks (1971), it is only by preparing the masses' imaginaries to be free from capitalist (now neo-liberal) cultural hegemony and its 'manufacturing of consent' that we will be able to act and establish a new horizon for humanity based on notions of commons, collective duties and collective consciousness of society.

What could archaeology do or be to participate into this ongoing conflict of imaginaries, now dominated by neo-liberal values? From my perspective, degrowth-driven archaeology can do its part by being a field of experimentation for our own post-capitalist emancipation, but most importantly for the emancipation of the communities we are interacting with. Through a degrowth experimental and non-dogmatic approach, we could give ourselves the means to mutate.

- By repositioning our activities in the sphere of politics as an 'anti-growth' activity, defending the primacy of common interests against abusive economic forces (corporate development or neo-liberal authoritarian states). Archaeologists, through civil disobedience, could regain dignity by acting collectively, accordingly to shared work ethics, and regain a sense of purpose by taking over the means of production, the cost of which would probably be the loss of our commercialized jobs, and our predominantly developer-based incomes.

- To continue to exist and play any kind of constructive role in communities, archaeologists could then regroup in non-profit cooperatives, which could be supported, through redistribution, by different means. This could be achieved by community-based concrete material support and completed or fully supported by a 'basic minimum income'. This would not be indexed on quantitative standards, but on the qualitative results (despite the difficulties of evaluating these - see Pudney 2019, 110) of decommodified labour, embedded in communities, until the latter decides collegially that the collaboration should end.

- Without direct financial exchange between actors in a non-profitable, 'no-growth'-based economy, archaeology would thus justify and sustain its existence uniquely from the fact that it participates actively in the the social life of the communities who have chosen to make archaeology and cultural heritage a significant common.

- Finally, a post-capitalist archaeology might have to be implemented through new forms of display and dissemination, notably by using artistic and radical expressions openly critical of the capitalist order (if it still prevails), and/or openly aiming to 're-enchant' the present.

At the time of writing this discussion, the COVID-19 pandemic is challenging the very existence of the present capitalist global configuration. Yet both neo-liberal states and corporations are fighting back with all their strength to save, as expected, not people, but the capitalist economic structure. It is still uncertain what consequences the coronavirus outbreak will have in the future, but whether the 'free-market economy' collapses or not, this is again (similar to the 2008 speculative/financial crisis) the time for us to engage in provocative changes. What the current crisis calls for is indeed a reimplementation of solidarity, with humanite at the centre of everything, in opposition to the failing neo-liberal economic system and its individualist, self-centred ideology. It is time to reorganize the role of the state and its public services, and if archaeology cannot be part of it without succumbing to free-market competition and being systematically undermined (as is the case in France today), the renaissance will have to occur outside the state. This will inevitably come with a major destabilization of the 'industry' before it mutates in a potential new and more modest, degrowth- or community-based configuration, free from the inherent competitive mentality imposed by neo-liberalism as the main characteristic of human interactions. To reiterate, that mutation would mean accepting that we will lose our jobs. I personally made peace with that prospect long ago and accepted its potential professional and personal consequences. Until things change, I will continue to challenge colleagues and 
students, by actively discussing the true nature of our current archaeological practices and proposing that together we continue exploring inventive alternatives.

\footnotetext{
Acknowledgments. I would like to thank all the scholars who agreed to participate in this contribution by further opening the debate about the degrowth movement, and helped me to clarify further my own arguments through their pertinent comments and positively challenging questions; the Fondation maison des sciences de l'homme (FMSH) for its financial support through the Fernand Braudel-IFER Post-doctoral Fellowship COFUND, and the UMR 8215 trajectoires and its members, which helped in conducting fieldwork in France and the United Kingdom, and contributed greatly to the current reflection; and the patient and kind proofreaders Dr Lucy Watson and Dr Sophie Violet Moore.
}

Archaeological Dialogues (2021), 28, 16-19

doi:10.1017/S1380203821000027

\title{
Archaeology, anarchism, decolonization, and degrowth through the lens of Frase's four futures
}

\author{
James Flexner
}

School of Philosophical and Historical Inquiry, University of Sydney, Sydney, Australia

Email: james.flexner@sydney.edu.au

As a scholar who is something of a theoretical and ideological bricoleur, taking bits and pieces that appear useful from many political projects and areas of scholarly enquiry, it is always gratifying to see other people coming to similar materials and arriving at similar conclusions. It suggests not only that one is on the right track, but importantly with projects like degrowth, that there are fellow travellers with whom to converse, discuss and debate across overlapping fields of theory and practice. As Zorzin points out in the discussion above, one of the issues facing the field is how to arrive at imagined utopian (or 'atopian') futures from what looks like an increasingly dystopian present.

The degrowth conversation in archaeology features many areas of clear overlap with anarchist archaeologies (Black Trowel Collective 2016; Flexner and Gonzalez-Tennant 2018; Rathbone 2017), which are themselves a utopian project. Both degrowth and anarchism propose a resistance, deconstruction or destruction of capitalism and simultaneously of the state mechanisms that enable it. Both would generally propose a shift towards more collegial and convivial ways of living, in which people autonomously choose their own associations, forms of labour and means of exchange within an environment of freely constituted and independent collectives. As with the degrowth movement, there are, of course, innumerable disagreements about how these things are to be accomplished, but at the least there are largely overlapping visions for the kinds of future societies we might construct within the shells of those crumbling around us.

Another source of wisdom hinted at in Zorzin's paper that bears further unpacking is the notion of 'decolonization' in archaeology (e.g. Menzies and Wilson 2020; Smith and Jackson 2006) not only of minds, but of the very economies and societies that we participate in. One possible route towards decolonization is to engage with knowledge produced by indigenous scholars of the areas where we happen to be located, ${ }^{1}$ and where we do our work, if those two things are not in the same place. For example, Bruce Pascoe's (2014) book Dark emu, despite providing some technical nits to pick from an archaeologist's perspective, provides a fascinating vision for an Australia where Country (not only environmental 'resources' but a variety of human and nonhuman actors) is looked after appropriately, and in which Indigenous knowledge and heritage are properly respected. Pascoe's observations concerning pre-European agriculture, marine resource management and even 'urbanism' in Aboriginal Australia would be important to integrate into any visions of degrowth in this continent. Considering the diversity of Aboriginal

(C) The Author(s), 2021. Published by Cambridge University Press. 